\title{
Against the use and publication of contemporary unethical research: the case of Chinese transplant research
}

\author{
Wendy C Higgins $\odot,{ }^{1}$ Wendy A Rogers $\odot,{ }^{1}$ Angela Ballantyne, ${ }^{2}$ Wendy Lipworth $\odot^{3}$
}

${ }^{1}$ Department of Philosophy, Macquarie University, North Ryde, New South Wales, Australia

${ }^{2}$ Centre for Biomedical Ethics, National University of Singapore; and Department of Primary Health Care and General Practice [Wellington], and Bioethics Centre [Dunedin], University of Otago, Wellington, New Zealand

${ }^{3}$ Sydney Health Ethics, The University of Sydney, Sydney, New South Wales, Australia

\section{Correspondence to} Professor Wendy A Rogers, Department of Philosophy, Macquarie University, North Ryde, NSW 2109, Australia; wendy.rogers@mq.edu.au

Received 19 December 2019 Revised 7 February 2020

Accepted 5 March 2020 Published Online First 1 July 2020

\section{Linked}

- http://dx.doi.org/10.1136/ medethics-2020-106535

- http://dx.doi.org/10.1136/ medethics-2020-106581

- http://dx.doi.org/10.1136/ medethics-2020-106719

- http://dx.doi.org/10.1136/ medethics-2020-106878

\section{Check for updates}

(C) Author(s) (or their employer(s)) 2020. No commercial re-use. See rights and permissions. Published by BMJ.

To cite: Higgins WC Rogers WA, Ballantyne A, et al. J Med Ethics

2020;46:678-684.

\section{ABSTRACT}

Recent calls for retraction of a large body of Chinese transplant research and of Dr Jiankui He's gene editing research has led to renewed interest in the question of publication, retraction and use of unethical biomedical research. In Part 1 of this paper, we briefly review the now well-established consequentialist and deontological arguments for and against the use of unethical research. We argue that, while there are potentially compelling justifications for use under some circumstances, these justifications fail when unethical practices are ongoing as in the case of research involving transplantations in which organs have been procured unethically from executed prisoners. Use of such research displays a lack of respect and concern for the victims and undermines efforts to deter unethical practices. Such use also creates moral taint and renders those who use the research complicit in continuing harm. In Part 2, we distinguish three dimensions of 'non-use' of unethical research: non-use of published unethical research, non-publication, and retraction and argue that all three types of nonuse should be upheld in the case of Chinese transplant research. Publishers have responsibilities to not publish contemporary unethical biomedical research, and where this has occurred, to retract publications. Failure to retract the papers implicitly condones the research, while uptake of the research through citations rewards researchers and ongoing circulation of the data in the literature facilitates subsequent use by researchers, policymakers and clinicians.

\section{INTRODUCTION AND BACKGROUND}

In February 2019, there was a call for the retraction of 445 papers reporting on the outcomes of Chinese transplant research. ${ }^{1}$ The authors of this call, published in February 2019 in BMJ Open, claimed that the papers should be retracted because the 'transplant community has failed to implement ethical standards banning publication of research using material from executed prisoners'. ${ }^{1}$ Taking organs from executed prisoners is in breach of internationally recognised ethical guidelines which require the autonomous and voluntary consent of donors and reject the possibility that consent can be obtained from individuals facing the death sentence. ${ }^{23}$ Further, guidance from The Transplantation Society (the peak international body for transplantation research and practice) prohibits presentation or publication of any subsequent research based on transplantation of organs taken from prisoners. ${ }^{4}$

Those authors calling for retractions noted that all of the papers included at least some data from transplants that occurred before the alleged move to a fully volunteer Chinese organ donor programme on 1 January 2015 and was thus prima facie in breach of international ethical guidance. Prior to 2010, the Chinese organ transplantation system had relied almost exclusively on organs procured from executed prisoners. ${ }^{5}$ Between 2010 and 2015, a pilot volunteer donor scheme commenced. By 2015 the Chinese government claimed to have moved to a $100 \%$ volunteer donor system. ${ }^{6}$ There is, however, evidence of ongoing killing of prisoners of conscience for their organs; ${ }^{7}$ and doubts remain regarding both numbers of voluntary donors in China and the voluntariness of in-hospital donations due to large payments to families of the deceased. ${ }^{8}$

In calling for a mass retraction, the authors of the review claimed that retention of the research in the literature raises questions of complicity and hypocrisy on the part of researchers, peer reviewers and journal editors who simultaneously publicly condemn and benefit from the use of executed prisoners' organs in research. ${ }^{1}$ The authors did not, however, engage in detailed arguments regarding use of unethical research or establish the different ways in which research may be 'used'. Nor did they locate their claim in the wider literature about the permissibility of using unethical research, where debates are ongoing. This paper addresses these issues.

In Part 1 , we systematically evaluate arguments for and against the use of unethical research $\left[{ }^{\mathrm{i}}\right]$ as relevant to Chinese transplant research. We conclude that the research should not be used; largely because the alleged abuses are ongoing. In Part 2, we articulate three dimensions of 'nonuse', including non-use of published results by researchers, non-publication, and retraction and argue that all three types of 'non-use' should be upheld in the case of Chinese transplant research. We encourage the research community to consider the relevance of our arguments to other instances of ongoing unethical research including gene editing and DNA surveillance.

\section{PART 1: AGAINST THE USE OF CHINESE TRANSPLANT RESEARCH}

There is a large literature on the morality of using unethical research, dating primarily from Nazi and

iHere we intend the term 'unethical research' to include both to research that is itself unethical (eg, lying to participants) and research that derives data from unethical practices, such as taking organs from executed prisoners. 
Japanese research during World War II. This literature contains strong arguments both for and against the use of unethical research, revealing ongoing disagreement and conflicting intuitions. Although these arguments have been most clearly articulated in relation to historical experiments, the arguments contained in this body of literature are relevant to current debates over the use of unethical research, including Chinese gene editing research, ${ }^{9}$ research using and facilitating genomic surveillance, ${ }^{10}$ and Chinese transplant research. While not identical to the historical cases, the current examples have salient similarities that raise questions about the potential value of using the research, about the value of access to knowledge in and of itself and how to balance such benefits against acknowledgement of harm to participants, and concern about lack of valid consent. For example, debate about the publication of data from Dr Jiankui He's unethical and illegal gene-editing experiments has recently resurfaced with the publication of He's data in Kiran Musunuru's new book. Musunuru is a cardiologist at the University of Pennsylvania and has justified publication on the grounds of public interest in access to the knowledge. Musunuru has argued (somewhat perplexingly) that because ethical flaws in He's work prevent its publication in mainstream peer-reviewed journals, the data should instead be published in non-traditional formats. ${ }^{9}$

Whether focused on historical or contemporary research practices, arguments for and against the use of unethical research can be broadly divided into those that are consequentialist and those that are deontological. Consequentialist arguments weigh the potential benefits of using unethical research against the potential harms of such use, whereas deontological approaches focus on the rightness of the actions involved, according to relevant principles or rules.

\section{Consequentialist arguments regarding use of unethical research}

Consequentialist arguments favouring the use of unethical research appeal to the potential value of that research: the more valuable the knowledge generated, the stronger the case for the permissibility of using the research. In the case of Chinese organ transplant research, the knowledge generated by the research might improve organ transplant practices and thus medical outcomes for future organ transplant recipients. However, this potential benefit must be weighed against the potential harms of using the data which include damage to medicine's reputation, ${ }^{11}$ sanctioning unethical research practices, ${ }^{12}{ }^{13}$ and-of particular importance in this context- encouraging, or failing to deter, ongoing unethical research. ${ }^{12}{ }^{14-16}$ The determination of whether or not it is permissible to use the results of unethical research depends on the balance between these benefits and harms.

In the case of Chinese organ transplant research, there are three key factors that influence the potential value of the research and thus the strength of the argument for its use: the research question, the research standards applied and the generalisability of the research findings to other contexts.

Despite the importance of assessing the likely or actual value of the research question, this can be challenging in practice. For example, a study identifying a novel transplant technique to improve organ quality may more rapidly lead to beneficial changes in clinical practice than one confirming the effectiveness of a widely used technique. But the value of any particular research study may not be immediately apparent, as for example, a single study with inconclusive results might critically contribute to a systematic review leading to a major advance in transplantation practice.
Research standards pertaining to scientific validity are integral to determining the value of biomedical research. Even research that addresses highly pertinent research questions will lack value if the research standards are insufficient to ensure scientifically valid results. In the case of Chinese transplant research, a discrepancy between the number of ethically sourced organs available in China and the number of ethically sourced organs researchers claim to have used in their studies suggests that researchers are either concealing or misrepresenting the source of the organs used in their research. ${ }^{1}$ While this kind of falsification is not in itself proof of lax research standards across the board, it should make us vigilant about the scientific validity of Chinese biomedical research. In fact, research integrity is an ongoing issue in China ${ }^{17}$ with specific concerns including inappropriate authorship, data fabrication, falsified results, and fake peer review. ${ }^{18} 19$

Misrepresenting the source of the transplanted organs impacts the potential value of the research findings by compromising generalisability. In China, evidence suggests that organs are procured from still living prisoners or immediately after execution; and that many of the 'donors' are young healthy prisoners of conscience. ${ }^{7}$ These organs differ in significant ways from organs that are donated after a donor dies of natural causes or trauma. This is especially the case for donations after death declared on circulatory criteria (DCD). In DCD cases, naturally dying donors may have prolonged periods of low blood pressure and poor oxygenation of their organs, which affects the number and quality of organs that can be subsequently transplanted. ${ }^{20} 21$ In contrast, organs taken at the point of death from healthy prisoners are not compromised by low oxygenation during the dying process. This makes them poor comparators in terms of transplant outcomes. If this difference is glossed over in the Chinese literature, the generalisability of the research findings is reduced in ways that are not immediately obvious to those unfamiliar with the Chinese system of organ procurement. In particular it may make Chinese transplantation research appear disproportionately successful and may harmfully distort clinical decision making about the risks and benefits of different transplant techniques in other countries.

From a consequentialist perspective, even if the results of a particular unethical research study are deemed to have value, these benefits must be weighed on a case-by-case basis against the harms of using them, of which there are several. The use of data from unethical research provides implicit validation of the research and affords a veneer of respectability to those researchers conducting unethical research. ${ }^{12} 1322$ This can either draw attention away from unethical research practices or, if noticed, can damage the reputation of the relevant research field and of the research endeavour more generally. Contemporary medical experimentation is perceived as legitimate and trustworthy in part because it is based on ethical codes that value and protect the interests of research participants. Such trust is crucial to the effective recruitment of research participants. ${ }^{23}$ The use of research in which these codes are breached can damage the reputation of biomedical research, ${ }^{23}$ which can in turn affect research funding from both government and philanthropic sources and discourage participation. While unethical research conducted in China might have limited impact on the perceived trustworthiness of researchers in Western countries, the reputations of Western researchers who are seen to condone this research by using it might be tainted by association. Thus, even if there may be scientific value to the research, this value might not outweigh the damage to medicine's reputation from using the research. ${ }^{113}$

The implicit sanctioning of unethical practices by ongoing use of unethical research fails to deter, and may even encourage, 
further unethical research practices. In the case of Chinese transplant research, there is little incentive for researchers in China to stop using data derived from unethical transplantation practices if they face no repercussions and journals continue to publish their research. The corollary of this is that researchers who are motivated by publication and citation might change their research practices if they know that studying transplantation using organs sourced from executed prisoners will preclude publication in international journals. ${ }^{222425}$

Despite significant potential harms, consequentialist arguments cannot unequivocally support Rogers et al's call for a mass retraction of 445 papers $^{1}$. On a consequentialist analysis the benefits of publishing the research would need to outweigh the harms. While we have identified the nature of the benefits and harms, the magnitude of each is hard to estimate, and is likely to vary between studies. The consequentialist analysis does not, therefore, clearly support or discredit Rogers et al's call for retractions. We now turn to deontological arguments to investigate alternative grounds for mass retraction.

\section{Deontological arguments regarding use of unethical research}

Deontological arguments are cited both by those favouring and those proscribing the use of unethical research. One argument for the moral acceptability of using unethical human research is that so doing honours the victims by ensuring that something good comes from their suffering. ${ }^{13} 2627$ This position is generally qualified by stipulating that using the research must have a high probability of saving lives, and that any publications must include an acknowledgement of the harms inflicted on the victims. ${ }^{262829}$ This approach is most commonly taken regarding use of research from Nazi experiments. This argument does not, however, seem applicable in the case of the Chinese transplant research. There is little acknowledgement of the source of the organs in the majority of the papers in the Rogers et al review. Four hundred and twelve (92.5\%) of the papers failed to report whether or not organs were sourced from executed prisoners, and there was certainly no acknowledgement that harms had been inflicted in the course of organ procurement. ${ }^{1}$

A second deontological argument for the use of unethically procured data concerns claims about the value of knowledge. Scientists commonly believe that knowledge has an inherent value and is a good in itself. A commitment to the freedom of scientific inquiry, freedom of expression and open sharing of research data follows from this basic premise. ${ }^{30} 31$ These values, which have been cited as the primary motivator for publishing He's unethical gene editing research, ${ }^{9}$ generate a strong presumption against ever censoring scientific knowledge. A strong commitment to sharing all research-generated knowledge would not impose any limits, irrespective of any ethical breaches or dangers. A less absolutist anticensorship position takes a precautionary approach, permitting limited censorship where there is a significant threat of, for example, using research results for bioterrorism. ${ }^{30}$ We argue that the ongoing nature of the unethical Chinese transplant research creates a second situation in which an absolutist position in favour of knowledge dissemination may be untenable, especially given recent findings that organ procurement in China involves crimes against humanity. ${ }^{7}$

While deontological arguments can permit the use of unethical research, they can also ground the counterclaim that use is impermissible, because so doing minimises or denies the wrongness of the methods used to produce the results and thereby fails to demonstrate proper respect for the victims. Furthermore, attempts to benefit from the moral wrong will undermine efforts to protest against unethical practices. The international biomedical
Box 1 Six ways of becoming morally complicit in the wrongdoing of others (adapted from Mellema) ${ }^{36}$

1. Commanding others to produce harm (eg, the head of a research team who instructs subordinates to conduct transplant research using biological material from executed prisoners).

2. Inducing others to produce harm (eg, employers who provide reputational, employment or financial rewards for the conduct of high-profile transplant research).

3. Advising others to undertake harmful conduct (eg, senior transplant officials in China who advise junior staff to put aside any concerns and participate in the research).

4. Consenting to the production of harm (eg, an ethics committee that approves harmful transplant research).

5. Celebrating or amplifying others when they produce the harm (eg, publishers and conference organisers that provide a platform for showcasing unethical research).

6. Failing to stop others from producing harm (eg, bystanders who fail to warn others of the conduct of unethical research).

community has an important duty to protest moral wrongs, especially where those wrongs are socially and legally sanctioned ${ }^{32}$ as the use of executed prisoners' organs has been in China. Victims of state sanctioned abuse and their families are ethically entitled to acknowledgement of the wrong that has occurred and deserve to see evidence that the transplant research community and others take this situation seriously by identifying perpetrators and holding them to account. Where these obligations to victims have not been satisfied, ongoing use of the research may contribute to whitewashing the methods used to procure the organs and amount to disrespect to the victims involved.

A second deontological set of reasons for not using unethically procured data relate to the potential moral damage to the users of the data stemming from moral complicity-the condition of being involved with others in an activity that is unlawful or immoral. Concerns about moral complicity and contamination are prevalent in bioethics. There is, for example, debate about whether researchers who use stem cell lines are complicit in the destruction of the embryos from which the cells were derived. ${ }^{32}$ In other examples, conscientious objectors claim they will be morally tainted and complicit in wrongdoing if they are required to refer patients to abortion and euthanasia services, or even refer patients to a different provider or provide information about the service. ${ }^{33-35}$

Gregory Mellema distinguishes between six different ways in which individuals can become morally complicit in the wrongdoing of others, all of which are pertinent to unethical transplant research (see box 1). ${ }^{3637}$

While not all complicity is morally blameworthy, blameworthy complicity can arise when an agent has failed to exercise proper care and good judgement in assessing the likelihood of subsequent harm from their action. In these cases, despite not intending for the harm to occur, the complicit agent is nonetheless reckless or negligent and therefore blameworthy. The degree of moral blameworthiness associated with complicity will vary across cases and depends in part on the degree to which the relevant wrongdoing is publicly known and guidance is available. We further discuss morally blameworthy complicity of publishers and editors regarding use of Chinese transplant in Part 2.

If unethical research conduct is ongoing, concerns about the moral implications of complicity through use relate in part to 
the future harm that will come from encouraging, condoning or platforming the research. But even use of historical research can morally 'contaminate' those who use it, rendering them complicit. For example, data generated by Nazi experiments on prisoners of war are deemed tainted due to their unethical provenance and connection to the victims. Future users must therefore handle the data with care or risk being contaminated by the moral taint. While this might sound rather nebulous and abstract, the view that data maintain a relationship to the data subject over time is the foundation for modern regulation in research ethics and data protection legislation. To use data in a manner that conflicts with the values of the data subject is recognised as a form of data harm. ${ }^{38}$ Concerns about harm persist even when the data subject is dead. ${ }^{39}{ }^{40}$ Data guardians are therefore increasingly recognised as having an important role in governing and safeguarding health data and ensuring appropriate uses over time. All these regulatory and governance mechanisms recognise an enduring connection between personal data and the data subject. Given that prisoners awaiting execution cannot give valid informed consent for organ donation, any research involving their organs carries the kind of moral taint discussed here: those organs and the subsequent data generated are irretrievably and permanently linked to those executed and the circumstances of their deaths.

In our view, deontological arguments provide robust grounds for claiming that unethical Chinese transplant research should not be used. The deontological argument that use honours the victims fails in this example, while the ongoing and egregious nature of the ethical breach seems one situation in which censorship of knowledge may be justified. Using the research displays a lack of respect and concern for the victims and undermines efforts to deter the practice. Ongoing use of the research creates moral taint because this use is inconsistent with the values of those from whom the organs were harvested, and those who use the research are thereby complicit in ongoing harms. Furthermore, we believe that these deontological arguments are compelling and would outweigh any utilitarian arguments in favour of use, even if Chinese transplant research did prove to be scientifically valid.

As discussed above, there are legitimate deontological and consequentialist arguments both for and against using unethical research. For the most part, previous literature has focused on historic research where there is no ongoing risk to research 'participants'. We take Chinese transplant research to be a special case in that there is evidence that procurement of organs from prisoners, and hence use of prisoners' organs in transplantation research, is ongoing. ${ }^{7}$ The seriousness and contemporaneous nature of this case distinguishes it from uses of historical research. In addition, the academic impact of the Chinese transplant research identified by Rogers et al is ongoing and in some cases substantial, with individual papers accruing high numbers of citations. For example, the 2011 paper by Yang et al in the Annals of Surgical Oncology ${ }^{41}$ has 650 citations identified on Google Scholar, while the recently retracted 2008 paper in Transplantation by Zheng et al has 419 citations. ${ }^{42}$ Thus, while there are valid arguments for the use of unethical research, where there is evidence of ongoing ethical violations as in the case of Chinese transplant research, we believe the arguments against use are stronger than the arguments in favour of use. Similar arguments prevail against the use of contemporary research based on gene editing and DNA surveillance.

\section{PART 2: WHAT CONSTITUTES 'NON-USE' OF UNETHICAL RESEARCH?}

Thus far we have argued that it is morally unjustifiable to use unethical Chinese transplant research. This, in turn, raises two questions: what does it mean to abstain from using unethical research and who is responsible for ensuring such 'non-use'? 'Non-use' can mean at least three things: (1) non-use of published unethical research by researchers, clinicians or policy makers; (2) non-publication; and (3) retraction. In the first case, responsibility for non-use falls squarely on researchers who should not use unethical research as the basis of further studies and on policy makers and practitioners who should refrain from making direct use of such research results. However, while this type of non-use is ethically warranted, it is hard to control or sanction, relies on the potential users being aware of the ethical breaches, and the rewards of publication persist for the researchers involved. It is crucial, therefore, that more 'upstream' versions of non-use are in place-most notably non-publication and retraction.

\section{Publication as use: the duties of publishers}

If we accept that non-publication and retraction are important (and are justified by the more general 'non-use' arguments articulated in Part 1) then much of the responsibility for non-use of research falls on journal editors and publishers. However, an objection may be raised that this is beyond the scope of responsibilities of editors and publishers. To respond to this objection, it is necessary to reflect on the purposes of academic publishing and on the corresponding roles and responsibilities of editors and publishers.

There are at least four, non-exclusive, purposes of academic publishing (and its processes of editorial and peer review): ${ }^{43-47}$

(1) to provide a complete record of scientific activity; (2) to facilitate the dissemination of novel ideas; (3) to ensure that only scientifically valid information is disseminated; and. (4) to maintain the integrity of science, protect research participants and reward those who act in ethical ways.

If we focus on the first three purposes (record keeping, dissemination and scientific quality) then it is not immediately obvious that research which is innovative and methodologically sound, yet unethical, should not be published (although as we argued above, the Chinese transplant research may not meet these criteria). But if the focus is on the fourth purpose (promoting integrity) then it follows that unethical research should not be disseminated, no matter its quality.

There is no simple answer to the question of which purpose(s) of publishing should be privileged but we contend that, in the context of contemporaneous unethical Chinese transplant research, the magnitude of the ongoing risk to those whose organs are used in the research and the threat to public and professional trust highlight the importance of editors and publishers promoting scientific integrity. Furthermore, there might be other-less risky-ways of maintaining a more or less complete scientific record and disseminating ideas that do not encourage and reward those who are acting unethically, such as an archive of unethical research without any of the career advantages of traditional academic publication.

The idea that editors and publishers have responsibilities when it comes to unethical research is reflected in the American Medical Association (AMA) position statement, which says in part that the results of cruel and inhumane experiments should virtually never be published ${ }^{48}$ unless: (1) the scientific validity of the research methods have been approved;. (2) there is no equivalent ethical source of data; and. (3) human lives would certainly 
be lost without the knowledge obtained from the data. These criteria are clearly not met in the Chinese transplant research as there is comparable research occurring in other countries that is more ethically robust, and it is virtually impossible to claim that any particular piece of transplant research would certainly save lives.

The AMA further requires that authors, peer reviewers and editors of medical publications sharing unethical research must:

- Disclose that the data derive from studies that do not meet contemporary standards for the ethical conduct of research.

- Clearly describe and acknowledge the unethical nature of the experiment(s) from which the data are derived.

- Provide ethically compelling reasons as to why the data are being released or cited, such as the need to save human lives when no other relevant data are available.

- Pay respect to those who were the victims of the unethical experimentation.

Authors, peer reviewers and editors in the transplant community have plainly failed to meet these disclosure standards in relation to publishing transplant research conducted in China. ${ }^{1}$

Publishing the Chinese transplant research raises questions of complicity and moral blameworthiness of editors and publishers. It could be argued that editors and publishers who publish unethical research are morally complicit in these unethical research practices if they are acting in ways that contribute to wrongdoing despite reasonably accessible guidance and evidence that such actions will lead to harm. In relation to Chinese transplant research, the use of executed prisoners' organs has been well documented, making it reasonable to expect peer reviewers or editors in the transplant community to have foreseen the potential for harm to arise from the ongoing sharing and use of the subsequent research. In addition there is published international guidance on this very topic, including from The Transplantation Society indicating that research using materials procured from executed prisoners is unethical and should not be 'celebrated or amplified' by accepting it for presentation and/or publication. ${ }^{4}$ Taken together, these warnings in the context of publicly available information about Chinese organ harvesting from prisoners strongly suggest morally blameworthy complicity on the part of editors and publishers.

The next question to address is whether editors and publishers have a responsibility to retract research that is identified as unethical after it has been published. This is a crucial question to answer because even the most skilled and conscientious editors and peer reviewers cannot be expected to detect all cases of unethical research-particularly if authors attempt to conceal unethical practices, either by omitting details or by direct falsifications (as occurred with the paper retracted from Liver International in 2017). ${ }^{49} 50$ Retraction is seen as an important mechanism of dealing with both unintended errors and misconduct in scientific research and publishing ${ }^{51}$ and, more generally, a key component in the process of scientific self-correction. ${ }^{52}{ }^{53}$ While practices across journals are not consistent, ${ }^{54}$ many biomedical journals have retraction policies, and many of these allow for retraction even without the authors' approval. ${ }^{55}$

If we accept that, in the case of contemporaneous unethical research, editors and publishers are obliged to block publication, then likewise they should take active steps to retract relevant articles that have evaded detection prior to publication.

In this regard, it is noteworthy that while historically research misconduct was limited to fabrication, falsification and plagiarism, recent research misconduct guidelines, including those produced by the Committee on Publication Ethics (COPE),${ }^{56}$ include 'unethical research' alongside misconduct as a justification for retraction. ${ }^{57}$ That said, we disagree with the position taken by COPE and others that retraction exists solely as a corrective measure with no punitive element. ${ }^{56}$ When the reason for retraction is unethical research, then the stigma attached to retraction can constitute a form of restorative justice, as well as sending an important message to the scientific community about unacceptable research practices. Retraction is a highly stigmatising activity therefore editors and publishers need to be certain that they have a strong case before retracting an article. Successful legal action is unlikely, but editors and publishers are vulnerable if they do not have clear evidence of wrongdoing. We do however, agree with $\mathrm{COPE}^{56}$ that, in the case of misconduct, retraction should not necessarily be delayed until other institutional processes have run their course. The journals that have to date retracted Chinese transplant papers have offered the authors and their institutions the opportunities to respond to queries about the research in question, ${ }^{5859}$ but do not appear to have delayed retraction awaiting the outcomes of any ongoing disciplinary processes at Chinese institutions.

For retractions to be effective, they must be prompt, transparent, clearly linked to the retracted article, clearly identifiable as a retraction and provide meaningful information about the reasons for retraction. However, there are no consistent systems or processes for identifying retracted articles across multiple electronic and print platforms, ${ }^{60}$ retracted articles continue to be cited, ${ }^{5461}$ and there is no mechanism of excluding retracted articles from existing secondary uses of the data such as systematic reviews. Retraction Watch, which currently includes 18 500 retracted articles, provides the largest database of retracted research, going some way to providing a public record. ${ }^{62}$ However Retraction Watch lacks secure ongoing funding and is not integrated across multiple bibliographic platforms, thereby hindering its usability and effectiveness. Technical solutions may help to make retractions more robust and consistent, ${ }^{60}$ but we believe that retraction should not be relied on as the sole mechanism of managing unethical research.

Given the shortcomings of retraction, additional measures might include more consistent and transparent independent investigation of unethical research, or, as mentioned above, a public register of unpublished unethical research, or of researchers associated with unethical research. Regarding investigation of unethical research, most research institutions have policies to deal with scientific misconduct. However, there may be less clear processes for dealing with research that is unethical in other ways, and the results of investigations into ethical breaches in research are rarely made public. To be an effective deterrent, institutions would need robust and transparent processes with independent review and publicly discoverable outcomes.

A public register of researchers (rather than of retracted papers) whose research has been retracted on ethical grounds (rather than other grounds, such as non-culpable error) might be a further measure to assist potential uses in identifying problematic research. This proposal raises practical questions and would need support from a transnational peak group such as the COPE.

Finally, the question remains as to whether other researchers should avoid any use of published but retracted research, given that retraction does not remove research from the public domain. The deontological arguments we have presented supporting nonuse provide ethical justification for researchers to refuse to use unethical research even if it would further their own research, however consequentialist arguments require researchers to weigh the benefits of using the research with the harms such as we have identified. Both types of argument have been used 
in relation to the use of the Eduard Pernkopf anatomical atlas, Topographical Anatomy of Man, which contains drawings of the bodies of executed prisoners and Jewish concentration camp victims. The atlas is renowned for the precision of its detailed drawings, leading to ongoing debate over its use despite the unethical source of bodies portrayed. ${ }^{63}$ However, as we have argued above, the ongoing nature of unethical organ procurement in China makes the use of Chinese transplant research a unique case, and researchers are ethically bound not to use the research.

\section{CONCLUSION}

Using, publishing and failing to retract publications based on ongoing unethical research are all morally problematic. These practices undermine the integrity of science, create complicity in unethical practices, corrupt the evidence base with potentially invalid data and sanction ongoing research ethics abuses. These are powerful reasons to support the call for the retraction of the Chinese transplant research that uses organs procured from nonconsenting executed prisoners, including prisoners of conscience. A wide scale retraction of all 445 papers in the cohort identified in Rogers $e t a l^{1}$ would be a powerful way of condemning the use of executed prisoners' organs, and in keeping with calls by The Transplantation Society dating back to $2007 .{ }^{4}$ Failure to retract the papers implicitly condones the practices underpinning that research and renders editors and publishers complicit in these practices, while uptake of the research through citations rewards rather than punishes the perpetrators. To date only 24 papers have been retracted, which highlights the need for the international scientific community to take a more active role in implementing agreed international standards for the reporting of transplant research and avoiding complicity in unethical research.

Contributors All authors contributed to refining the research topic, performing research and drafting content. WCH and WAR led on drafting the penultimate version. All authors contributed to revisions and approved the final version for submission.

Funding The authors have not declared a specific grant for this research from any funding agency in the public, commercial or not-for-profit sectors.

Competing interests WAR reports being a Director of the NGO 'International Coalition to End Transplant Abuse in China' and is chair of its international advisory committee. $A B$ reports being a member of the International Advisory Committee and the New Zealand Advocacy \& Initiatives Committee (NZAIC) of the International Coalition to End Transplant Abuse in China. WL reports grants from National Health \& Medical Research Council, grants from Australian Research Council, outside the submitted work.

Patient consent for publication Not required.

Provenance and peer review Not commissioned; externally peer reviewed.

Data availability statement There are no data in this work

\section{ORCID iDs}

Wendy C Higgins http://orcid.org/0000-0003-1357-8330

Wendy A Rogers http://orcid.org/0000-0001-9186-870X

Wendy Lipworth http://orcid.org/0000-0002-0234-657X

\section{REFERENCES}

1 Rogers W, Robertson MP, Ballantyne A, et al. Compliance with ethical standards in the reporting of donor sources and ethics review in peer-reviewed publications involving organ transplantation in China: a scoping review. BMJ Open 2019:9(2):1-11.

2 World Health Organization. WHO guiding principles on human cell, tissue and organ transplantation. Transplantation 2010;90(3):229-33.

3 World Medical Association. WMA statement on organ and tissue donation. Available: https://www.wma.net/policies-post/wma-statement-on-organ-and-tissue-donation/ [Accessed Dec 2019]
4 Tibell A. The transplantation Society's policy on interactions with China. Transplantation 2007:84(3):292-4.

5 Huang J. Ethical and legislative perspectives on liver transplantation in the People's Republic of China. Liver Transp/ 2007:13(2):193-6.

6 Huang J-F, Zheng S-S, Liu Y-F, et al. China organ donation and transplantation update: the Hangzhou resolution. Hepatobiliary Pancreat Dis Int 2014;13(2):122-4

7 China Tribunal. Final judgment report. Available: https://chinatribunal.com/finaljudgement-report/ [Accessed Dec 2019].

8 Robertson MP, Hinde RL, Lavee J. Analysis of official deceased organ donation data casts doubt on the credibility of China's organ transplant reform. BMC Med Ethics 2019:20(1):79.

9 Nature Editorial. When the world needs to know. Nature Biotechnol 2020;38.

10 Moreau Y. Crack down on genomic surveillance. Nature 2019;576(7785):36-8.

11 Beecher HK. Ethics and clinical research. 1966. Bull World Health Organ 2001;79(4):367-72.

12 Kaveny MC. Appropriation of evil: cooperation's mirror image. Theol Stud 2000;61(2):280-313.

13 Bogod D. The Nazi hypothermia experiments: forbidden data? Anaesthesia 2004:59(12):1155-6.

14 Ridley A. Ill-gotten gains: on the use of results from unethical experiments in medicine. Public Aff Q 1995;9(3):253-66.

15 Post SG. Nazi data and the rights of Jews. J Law Relig 1988;6(2):429-33.

16 Green RM. Benefiting from 'evil': an incipient moral problem in human stem cell research. Bioethics 2002;16(6):544-56.

17 Zeng W, Resnik D. Research integrity in China: problems and prospects. Dev World Bioeth 2010;10(3):164-71.

18 Yi N, Nemery B, Dierickx K. Perceptions of research integrity and the Chinese situation: in-depth interviews with Chinese biomedical researchers in Europe. Account Res 2019;26(7):405-26.

19 Rivera H. Fake peer review and inappropriate authorship are real evils. J Korean Med Sci 2019;34(2):e6.

20 Coffey J, Wanis K, Monbaliu D, et al. The influence of functional warm ischemia time on DCD liver tranplnat recipients' outcomes. Clin Transplant 2017;10.

21 Brennan C, Sandoval P, Husain S, et al. Impact of cold and warm ischemia time on outcomes for kidneys donated after cardiac death [abstract]. Am J Transplant 2019;19.

22 Schafer A. On using Nazi data: the case against. Dialogue Can Philos Assoc 1986;25(3):413-9.

$23 \mathrm{Liu} \mathrm{H}-\mathrm{E}$, Li M-C. Factors influencing the willingness to participate in medical research: a nationwide survey in Taiwan. PeerJ 2018:6:e4874.

24 Hunter D. Editorial: the publication of unethical research. Res Ethics 2012;8(2):67-70.

25 Angell M. The Nazi hypothermia experiments and unethical research today. N Engl J Med 1990:322(20):1462-4

26 Moe K. Should the Nazi research data be cited? Hastings Cent Rep 1984;14(6):5-7.

27 Atlas MC. Ethics and access to teaching materials in the medical library: the case of the Pernkopf atlas. Bull Med Libr Assoc 2001;89(1):51-8.

28 Halpin R. A history of concern: the ethical dilemma of using Nazi medical research data in contemporary medical and scientific research [master's thesis]. Sydney: University of Sydney, 2008.

29 Greene V. Can scientists use information derived from the concentration camps? Ancient answers to new questions. In: Caplan A, ed. When medicine went mad: bioethics and the Holocaust. Totowa, NJ: Humana Press, 1992: 155-72.

30 Selgelid MJ. A tale of two studies; ethics, bioterrorism, and the censorship of science. Hastings Cent Rep 2007;37(3):35-43.

31 Schweber S. In the shadow of the bomb: Bethe, Oppenheimer, and the moral responsibility of the scientist. Princeton University Press: Princeton, NJ, 2002.

32 Siegel AW. Temporal restrictions and the impasse on human embryonic stem-cell research. Lancet 2004;364(9429):215-8.

33 NeJaime D, Siegel R. Conscience wars: complicity-based conscience claims in religion and politics. Yale Law J 2015;124:2516-91.

34 Minerva F. Conscientious objection, complicity in wrongdoing, and a not-so-moderate approach. Camb Q Healthc Ethics 2017;26(1):109-19.

35 Hallagan and Anor V medical Council of NZ: high Court of new Zealand Wellington registry 2010.

36 Mellema G. Collective responsibility. Amsterdam: Rodopi Press, 1997.

37 Cohen J. Casting the first stone: who can, and who can't, condemn the terrorists? Royal Institute of Philosophy Supplement 2006:58:113-36.

38 Metcalf J, Crawford K. Where are human subjects in big data research? the emerging ethics divide. Big Data Soc 2016.

39 Shaw DM, Gross JV, Erren TC. Data donation after death. EMBO Rep 2016;17(1):14-17.

40 Hoeksema K, Wee R, Macdonald A, et al. Where to from here? Posthumous healthcare data, digital e(lectronic)-mortality and New Zealand's healthcare future. N Z Med J 2017;130(1459):64-70

41 Yang Z, Zhou L, Wu L-M, et al. Overexpression of long non-coding RNA HOTAIR predicts tumor recurrence in hepatocellular carcinoma patients following liver transplantation. Ann Surg Oncol 2011:18(5):1243-50.

42 Zheng S-S, Xu X, Wu J, et al. Liver transplantation for hepatocellular carcinoma: Hangzhou experiences. Transplantation 2008:85(12):1726-32.

43 Teixeira da Silva JA. A call for greater editorial responsibilities. Science Editing 2015;2(2):89-91 
44 Sarker S, Agarwal R, Goes P, et al. Roles and responsibilites of a senior editor.. J Assoc Inf Syst 2015;16.

45 Pittenger DJ. Intellectual freedom and editorial responsibilities within the context of controversial research. Ethics Behav 2003;13(2):105-25.

46 Pereira V. Journal editors as philosopher kings: duties and responsibilities of academics in a changing world. South Asian Hist Cult 2017:8(3):360-4.

47 Albert DM, Liesegang TJ, Schachat AP. Meeting our ethical obligations in medical publishing: responsibilities of editors, authors, and readers of peer-reviewed journals. Arch Ophthalmol 2005;123(5):684-6.

48 American Medical Association. Release of data from unethical experiments. Available: https://www.ama-assn.org/delivering-care/ethics/release-data-unethical-experiments [Accessed Dec 2019].

49 Rogers WA, Fiatarone Singh MA, Lavee J. Papers based on data concerning organs from executed prisoners should not be published: response to Zheng and Yan. Liver Int 2017;37(5):771-2.

50 Rogers WA, Fiatarone Singh MA, Lavee J. Papers based on data concerning organs from executed prisoners should not be published. Liver Int 2017;37(5).

51 Steen RG. Retractions in the scientific literature: is the incidence of research fraud increasing? J Med Ethics 2011;37(4):249-53.

52 Sheth BP, Thaker VS. Scientific retraction: a synonym for pseudoscience? Acta Bioeth 2014;20(1):93-7.
53 Drimer-Batca D, laccarino JM, Fine A. Status of retraction notices for biomedical publications associated with research misconduct. Research Ethics 2019;15(2):1-5.

54 Elia N, Wager E, Tramèr MR. Fate of articles that warranted retraction due to ethical concerns: a descriptive cross-sectional study. PLoS One 2014;9(1):e85846.

55 Resnik DB, Wager E, Kissling GE. Retraction policies of top scientific journals ranked by impact factor. J Med Libr Assoc 2015;103(3):136-9.

56 Committee on Publication Ethics. Retraction guidelines, 2019. Available: https://doi. org/10.24318/cope.2019.1.4 [Accessed Dec 2019].

57 Dal-Ré R, Bouter LM, Cuijpers P, et al. Should research misconduct be criminalized? Res Ethics 2020;561(7723).

58 The PLoS One Editors. Retraction: a scoring model based on neutrophil to lymphocyte ratio predicts recurrence of HBV associated hepatocelluar carcinoma after liver transplantation. Transplantation 2019;14:e0220418.

59 Chapman JR, Stock P, Haberal M. Organs from exectued people are not a source of scientific discovery. Transplantation 2019:103(8):1534-5.

60 Bakker C, Riegelman A. Retracted publications in mental health literature: discovery across bibliographic platforms. J Libr Sch Commun 2018;6(General Issue):eP2199.

61 Madlock-Brown CR, Eichmann D. The (lack of) impact of retraction on citation networks. Sci Eng Ethics 2015;21(1):127-37.

62 Retraction watch database. Available: http://retractiondatabase.org/RetractionSearch. aspx [Accessed Oct 2019].

63 Mackinnon S. When medical information comes from Nazi atrocities. BMJ 2020;368. 